\title{
Project Management Risks in the Sphere of Housing and Communal Services
}

\author{
Victoria Borkovskaya* \\ Moscow State University of Civil Engineering, Yaroslavskoe shosse 26, Moscow, 129337, Russia
}

\begin{abstract}
This paper shows a project risk management system model allowing enterprises to better identify risks in the sphere of housing and communal services and to manage them throughout the life cycle of the project. It shows the most popular methods of risk probability assessment and tries to indicate the advantages of the robust approach over the traditional methods. Modern development of project management as well as the accumulated knowledge and experience in this field made it possible to integrate project management knowledge into a single system model. Within the framework of this model, standard and robust approaches are applied and expanded for the tasks of project data analysis. The suggested algorithms used to assess the parameters in statistical models allow to obtain reliable estimates. In this study, the classification of risks was determined by the degree of relevance. I conducted an analysis of statistical data, such as requests for maintenance of housing stock of different service lives. The frequency of failures in the work of housing organizations was determined and the probability of accidents was calculated. Taking into account these calculations, the housing stock was graded according to the degree of admissibility of the risk of its maintenance.
\end{abstract}

\section{Introduction}

This research is aimed at studying the methodological and organizational problems of professional risk management in the sphere of housing and communal services. These are defined as "a complex of economic sectors that ensure the functioning of residential buildings that create safe, comfortable and comfortable living and the presence of people (consumers) in them. It also includes social infrastructure facilities for servicing residents" [1] In other words, this paper examines enterprises and systems within and across public housing, public buildings and public utilities (e.g., enterprises providing electricity, water, gas and other products and services).

The modern development of the Russian economy is becoming increasingly oriented towards the introduction of the latest technology and technologies in all its spheres. At the same time, the solution of the quality problem of any of the spheres of the economy directly depends on the economic and social policy pursued by the state.

\footnotetext{
*Corresponding author: BorkovskayaVG@mgsu.ru
} 
Project risk management involves a set of methodology, methods, technical and software tools used in the design and implementation of projects, in this case in the field of housing and communal services, that facilitates the consideration and minimization of risks, ie unique processes that are time-limited and resource-intensive.

A significant part of models and mechanisms for managing project risks are optimization problems, which are, as a rule, complex and multiextremal.

In this process, the data itself largely determines the outcomes, and the problem of their quality, i.e. correctness, interpretability, portability, control, redundancy, security, etc., come to the fore. This problem is intensified in the interstate communication, both at the level of standardization specialists and at the level of specific commercial structures. That is why this issue is given increased attention at the federal level.

\section{Methodology}

Risk in project management is often understood as a random event, which in case of its implementation has a negative impact on the project (the case when this event has a positive impact on the project is called an opportunity). This negative impact can be manifested in the increase in the deadlines for the completion of work, and as a result, the project completion deadline, the overestimation or underestimation of the cost of work and, as a result, the budget excess or deficit, the quality of work, etc. We will mainly consider temporary risks (exceeding the deadlines for performance of work) and cost risks (exceeding the cost of work).

Risks are described by two main characteristics: The probability of occurrence of a risk, since any project is by definition unique, it is not always possible or necessary to count on the availability of statistical data. At best, you can use the notion of subjective probability, which relies on expert assessments. Since expert assessments are generally rather crude, it seems event and the consequences (damage) in its occurrence. A general characteristic is the degree of influence (risk rank), which is the expected damage (the product of the probability by the amount of damage). [2]

The quality of risk assessments is determined by both the set of actors going into the formulas and the formulas themselves. [4] In recent times, high-quality risk assessments, including estimates of probability, damage, and degree of influence, have become widespread (especially in practice). This is because probabilistic estimates require statistics or, in any case, a certain frequency of events. However natural to use qualitative estimates of probability, damage, and degree of influence. The most common three-point scale of probability and damage estimates: small risk (1), medium risk (2) and high risk (3). [2-4]

A small risk is deemed to have virtually no effect on the parameters of the project, and it is usually not taken into account. We note that qualitative estimates hide their quantitative counterparts. For example, the probability of a risk event from 0 to 0.05 can be attributed to a small risk, from 0.05 to 0.3 to the average, and above 0.3 to a high risk. Similarly, if we bear in mind temporary risks, deviations of about $5 \%$ of the duration of the project can be attributed to small risks, from 5\% to $30 \%$ to medium risks, and above $30 \%$ to high risks. These boundaries today are also determined by expert means and largely depend on the terms of the project (rigidity of sanctions for failure to complete the project, for exceeding the budget, etc.) As to the degree of influence, different methods are used here. The simplest way is to determine the degree of influence, as the product of the risk assessment for damage assessment (this technique is used in particular in the Savings Bank of Russia). We get a six-point scale of the degree of influence $1,2,3,4,6,9$. Its disadvantage is that it is uneven. Often a three-point scale of assessments of the degree of influence is used: small, medium and high. In this case, to obtain estimates of the degree of influence, a convolution 
matrix of probability estimates and damage estimates is determined. An example of such a matrix is shown below (Table 1).

Table 1. Matrix 1

\begin{tabular}{|c|c|c|c|}
\hline 3 & 2 & 3 & 3 \\
\hline 2 & 2 & 2 & 2 \\
\hline 1 & 1 & 1 & 2 \\
\hline $\mathrm{y}$ & 1 & 2 & 3 \\
\hline $\mathrm{B}$ & 1 & \\
\hline
\end{tabular}

You can see a certain priority ranking. Namely, the average damage, with a low probability, experts consider to have a greater degree of influence (score 2) than a small damage at an average probability (score 1 ).

If the probability estimate has a higher priority than the damage estimate, the matrix will look like (Table 2)

Table 2. Matrix 2

\begin{tabular}{|l|l|l|l|}
\hline 3 & 2 & 2 & 3 \\
\hline 2 & 1 & 2 & 3 \\
\hline 1 & 1 & 1 & 2 \\
\hline $\mathrm{y}$ & 1 & 2 & 3 \\
\hline
\end{tabular}

Finally, if both estimates are equally priority, then the matrix will be symmetric (Table 3).

Table 3. Matrix 3.

\begin{tabular}{|l|l|l|l|}
\hline 3 & 2 & 3 & 3 \\
\hline 2 & 2 & 2 & 3 \\
\hline 1 & 1 & 2 & 2 \\
\hline $\mathrm{y}$ & 1 & 2 & 3 \\
\hline $\mathrm{B}$ & &
\end{tabular}

The choice of the convolution matrix is of great importance, since the resulting impact assessment is the basis for identifying the most significant risks and developing appropriate response measures (risk reduction, risk transfer, risk acceptance or risk evasion). One of the main measures of response is risk reduction that is, carrying out a number of activities that reduce either the probability, or the damage, or both. Consider the task of reducing the degree of risk to the required level with minimal costs.

Let there be $n$ measures to reduce the risk, that is, to reduce the probability of either damage, or both. Let us first consider the case when there is a set $\mathrm{Q}$ of $\mathrm{n}$ measures to reduce the likelihood of occurrence of a risk event and a set of $\mathrm{P}$ of $\mathrm{m}$ mitigation measures. To assess the effect of risk reduction measures, it is advisable to proceed to quantitative estimates of probability and damage. Let $\mathrm{p}_{\mathrm{c}}$ and $\mathrm{p}_{\mathrm{b}}$ be the boundary values of the probability. If the probability of a risk event lies in the half-open interval $\left(0 ; p_{n}\right]$, then this is a small probability on a qualitative scale, if in the half-open interval $\left(\mathrm{p}_{\mathrm{n}} ; \mathrm{p}_{\mathrm{c}}\right]$, then the average probability, and if in $\left[\mathrm{p}_{\mathrm{c}} ; 1\right)$, then high. Similarly, $\mathrm{q}_{\mathrm{н}}$ and $\mathrm{q}_{\mathrm{c}}$ Limit values of damage Next, we denote $a_{i}$ - the effect from the $i$-th measure to mitigate the damage, ci - costs for the $\mathrm{i}$-th measure to reduce the probability, $s_{i}$ - costs for the $\mathrm{i}$-th measure to reduce the 
damage. We first consider the problem of reducing probability. Denote $\mathrm{x}_{\mathrm{i}}=1$, if the event is included in the risk management plan, $x_{i}=0$, otherwise. Assuming that the effects are summed, the total effect can be written as:

$$
B(x)=\sum_{i=1}^{n} a_{i} * x_{i}
$$

Let $\mathrm{p}$ be the existing probability level and $\mathrm{p}>\mathrm{p}_{\mathrm{c}}$, that is, the probability is high. To reduce the probability to an average level, it is necessary to provide an effect of at least $\left(p-p_{c}\right)$, and to a low level of effect no less than $\left(\mathrm{p}_{\mathrm{o}}-\mathrm{p}_{\mathrm{H}}\right)$.

Formulation of the problem. Define $\mathrm{x}_{\mathrm{i}} \mathrm{i}=\overline{1, n}$ minimizing.

$$
C(x)=\sum_{i=1}^{n} c_{i} * x_{i}
$$

Under restriction

$$
\sum_{i=1}^{n} a_{i} * x_{i} \geq p-p_{c}
$$

By replacing the variables $\mathrm{z}_{\mathrm{i}}=1-\mathrm{X}_{\mathrm{i}}, \mathrm{i}=\overline{1, n}$, the problem reduces to the classical knapsack problem (see Appendix): to determine $\mathrm{z}_{\mathrm{i}}, \mathrm{i}=\overline{1, n}$, maximizing

$$
\sum_{i=1}^{n} Z_{i} * c_{i}
$$

Under restriction

$$
\sum z_{i} * a_{i} \leq \sum_{i} a_{i}-\left(p-p_{c}\right)=A
$$

The conclusion. As is known (see the appendix), the solution of the knapsack problem with constraint A gives solutions for any smaller values, that is, for $A_{1}=\sum_{i} a_{i}-\left(p-p_{c}\right) \leq A$ that is, the minimum costs to ensure a low level risk.

\section{Results and Discussion}

The priority direction of reforming the sphere of housing and communal services is the development of market relations in the housing and communal sector, which should be accompanied by the search for methods of state (municipal) regulation, in particular, through tariffs. The objective necessity of such regulation is connected with the peculiarities of housing and communal services, first of all, their uninterrupted operation, i.e. the impossibility of refusing to receive them for a long period, as well as the inability to compensate for underserved services.

Influence on the nature of market relations in housing and communal services and the features of the housing stock in Russia, in particular, is that, despite the large volumes of privatized apartments, most of the residential houses remain municipal. Municipal property is also a unified system for utilities, i.e. the relevant authorities are required to control the use of municipal property. Previously listed features, as well as high social significance of housing and communal services make it impossible to switch to completely free pricing. Prices, as well as tariffs determined on their basis, should remain a means of implementing a social and economic policy in the housing sector.

The development of market relations in the housing and utilities sector will lead to an increase in the uncertainty that always occurs when moving to the market. The 
concretization of the risk category with regard to the activities of housing and communal enterprises allows us to conclude that the risk is the uncertainty associated with the cost of maintenance costs of housing stock, or the likelihood of an unfavorable outcome (in this case, not only for the enterprise, but also for its end users - residents ) in connection with the maintenance of housing. It has now become clear that reducing the uncertainty, and hence the risks in the housing and communal sector, is a task that has reached a nationwide scale, on the basis of which the socio-economic security of the country depends. The solution of this problem must be linked both to the improvement of the housing stock condition and to the reduction of uncertainty within the industry, primarily by improving the methodology for the formation of tariffs, i.e., to increase the validity of determining the costs of specific utilities. In addition, in the sphere of housing and communal services, there are also objective sources of sectoral risks that may not be present in other countries - e.g., in the RF, there is a single network of water, heat and power supply often with significantly worn-out networks within the municipality. Therefore, failures in any one link in the housing and utilities sector, even without direct access to the population, can lead to considerable damage, even to people's lives and health (for example, accidents at a thermo plant and power station in winter). In this regard, it is necessary to note the difficulties in managing risks directly at enterprises engaged in housing services, which in many ways are an intermediate link between resource-producing monopoly enterprises dictating their terms to these enterprises, and often municipal authorities. [5-7]

In addition, risks in the housing and communal services need to be considered in the regional aspect, when there is an increase in many municipalities due to budget deficit and low real incomes, which are the main sources of financing for the housing and communal services sector. The probability of underfunding, i.e. the financial risks of housing and communal enterprises in these conditions are increasing many times. Therefore, the resolution of issues of intergovernmental fiscal relations, as well as the implementation of large-scale socio-economic programs, are the most important directions for reducing regional risks in housing and communal services. [8-9]

Separately, it is necessary to note the high legal risks caused by historical features of the object of servicing the municipal housing stock, which is represented mostly by multi-store apartment houses. These houses are the property of the municipality, which partially leases them, as well as private property of citizens who have privatized their apartments. Lack of appropriate legal registration of relations in connection with the maintenance of housing stock and inconsistencies in the housing and civil codes, for instance, make many court proceedings difficult due to non-payment of utility bills, use of public places, etc. [10-12]

In order to classify risks by the degree of admissibility, I analyzed statistical data applications for maintenance of housing stock of different service lives and the frequency of disruptions in the work of housing organizations, to calculate the probability of accidents. Taking into account these calculations, the housing stock was graded according to the degree of admissibility of the risk of its content (Table 4).

Calculations for the housing stock of Moscow showed that in percentage terms this fund is distributed as follows: risk-free zone - $41.5 \%$, zone of acceptable risk - $36.7 \%$, critical risk zone $-11.4 \%$ and zone of catastrophic risk - 10.4\%. [13]

Due to are latively predictable $80-90 \%$ of the collection of the rent from the population of public housing provides the company relatively stable, albeit relatively low income. However, as barriers to the development of commercial activities are removed, municipal unitary enterprises will begin to provide additional paid services already at market prices. Accordingly the commercial risks of this activity will be somewhat higher than in the provision of the basic range of services. Many entrepreneurs already have an adequate understanding of the problem of commercial risks in housing and communal services, so the interest in this area, not yet divided by the private business, is growing every day. 
Table 4. Determination of zones of admissibility of housing stock risk in connection with its maintenance.

\begin{tabular}{|c|c|c|c|}
\hline $\begin{array}{l}\text { Risk-free } \\
\text { zone }\end{array}$ & $\begin{array}{c}\text { Area } \\
\text { of permissible risk }\end{array}$ & $\begin{array}{l}\text { Zone } \\
\text { critical risk }\end{array}$ & $\begin{array}{c}\text { Zone } \\
\text { catastrophic risk }\end{array}$ \\
\hline $\begin{array}{l}\text { Costs insignificant, } \\
\text { profit earning } \\
\text { New housing fund of } \\
\text { high-quality } \\
\text { construction taking } \\
\text { into account the } \\
\text { warranty period } \\
\text { Depreciation - 0-20\% }\end{array}$ & $\begin{array}{l}\text { Repair work is mainly } \\
\text { of a current nature All } \\
\text { costs are included in } \\
\text { the price } \\
\text { Housing stock with a } \\
\text { wear amount of } 21 \text { - } \\
40 \%\end{array}$ & $\begin{array}{l}\text { Significant volumes of } \\
\text { capital work } \\
\text { Emergence of accidents, } \\
\text { work to eliminate them } \\
\text { Loss of resources, losses } \\
\text { Housing stock with wear } \\
\text { and tear } 41-60 \%\end{array}$ & $\begin{array}{l}\text { Work in emergency } \\
\text { mode, a large number } \\
\text { of accidents Huge } \\
\text { losses, irreversible } \\
\text { process of deteriorating } \\
\text { housing conditions } \\
\text { Unsuitable for } \\
\text { residence Housing } \\
\text { stock with deterioration } \\
\text { of } 61 \% \text { or more }\end{array}$ \\
\hline
\end{tabular}

Separately, it is necessary to say something about high production risks. The production risk with respect to the housing and utilities sector is characterized as a danger of potential loss of resources or shortfall in income, as well as the appearance of additional losses in comparison with the option designed for rational use of resources. [14-15]

The activities of utilities are affected by all of the risks considered, but the degree of their impact is different. Experts differentiated the degree of influence of these risk factors on the activities of enterprises (Fig. 1).

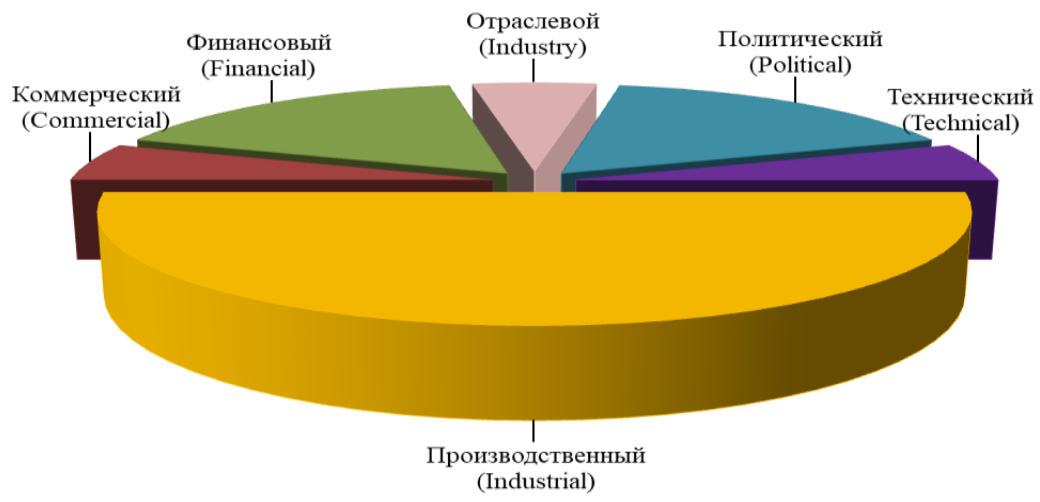

Fig. 1. The degree of influence of risk factors in utilities.

This author believes that it is necessary to move to a more systematic system for recording and dividing the risks of accidents in the housing sector. To do this, it is necessary to assess at the stage of price determination and contract conclusion what is the degree of production risk in servicing this housing stock and what financial compensation, for the most part from the municipality, the contractor will have to undertake for servicing it. The number of these accidents is inversely related to the compliance with the terms of the current and major repairs. By investing additional funds, managers can increase the lifespan of the building and significantly reduce the accident rate, so that the probability of accidents will decrease. [16] Currently, with housing stock having varying degrees of depreciation, the main efforts of housing and utility organizations are directed to maintaining the housing in in a normal but sometimes (often?) dilapidated state, and, of course, a minimum of work is carried out on houses with a service life of 10-15 years. This 
period of depreciation, in our opinion, requires very close attention when the life cycle of the building and its construction and maintenance costs are being calculated.

Currently, the costs of emergency recovery work are not well planned. At many enterprises the costs for this type of work are not included at all in the composition of costs, i.e. are not taken into account when forming tariffs. Liquidation of the consequences of accidents is carried out at the expense of funds intended for current and capital repairs, which distorts the structure of planned costs and leads to a decrease in the reliability of services. Scheduled preventive maintenance frequently gives way to emergency repair work today. In order to increase the justification of expenses for housing and communal services, we believe that it is necessary to take into account the risk that relates not so much to the object of influence (housing stock) as to the type of activity, i.e. to the maintenance and maintenance of this facility. At the same time, the condition of the servicing object - the residential building - is directly related to the growing uncertainty in the process of its servicing. In assessing the production risk, we are primarily interested in the fate of the whole object and the measure of danger and the degree of potential damage in the work of a housing-operating enterprise as a result of a failure, i.e. accidents, as well as the likelihood of harm to both physical and moral character of the final consumer of housing and communal services - the inhabitants. At the same time, we are interested not only in the principle of compensation for losses, but in the emergence of the possibility of preventing damage that may result from an accident. Based on the studies carried out, an algorithm for recording emergency recovery work was developed for the economic justification of expenses for the implementation of these activities as part of the cost of housing maintenance services. Calculated in this way the amount of funds for emergency work can be realistically estimated. This could be fixed in the form of an insurance fund. Separately, it should be noted that for housing stock belonging to critical and catastrophic risk zones, responsibility should be distributed between enterprises and the municipality, which must compensate for the increased costs due to the worn condition of houses and other factors, in order to prevent price discrimination of those living in this fund. Enterprises under this scheme of work can be set up to identify internal and external factors that affect the amount of risk, to assess and determine the economic feasibility of investing funds in improving repair and maintenance technologies and materials, and in conducting preventive maintenance work. These measures will save money for the liquidation of accidents, and for the municipality this will mean improving the state of urban residential real estate and reducing the use of budget funds to eliminate the consequences of emergencies. [17-20]

\section{Conclusions}

In conclusion, the application of improved enterprise risk management practices can alleviate current problems in the construction and management of housing, public buildings and utilities, both as individual, discrete entitites as well as across municipalities and states. Presently, the development of housing and communal services is hampered by an unfavorable ratio of risk-return factors. While the high degree of risk that exists in these enterprises is typically planned to be compensated by higher profitability, this is almost impossible in practice because of the great social burden that subsequent and unplanned higher prices to the consumers would require. Therefore, in order to improve the ratio of profitability to risk, to increase the investment attractiveness of housing and other public enterprises, it is necessary for the enterprises as well as the state and the municipality to appropriately and thoroughly assess and manage the risks of their activities in the planning, construction and management stages. 
I want to thank Professor Richard L. Roe of Georgetown University Law Center for his editorial assistance with this paper.

\section{References}

1. Borkovskaya V.G. Economic cooperation in housing maintenance organizations. Dissertation. Moscow 2002.

2. Borkovskaya V.G. Complex models of active control systems at the modern developing enterprises. Advanced Materials Research (Volumes 945-949). Chapter 22: Manufacturing Management and Engineering Management. June 2014. Pages 30123015. DOI: 10.4028/www.scientific.net/AMR.945-949.3012.

3. Burkova I.V. The method of network programming in problems of nonlinear optimization. I.V. Burkova // Automation and telemechanics. - 2009.-No. 10.-P.15-21.

4. Burkov V.N., Novikov D.A., Shchepkin A.V. (2015) Simulation Models for Control Mechanisms in Ecological-Economic Systems. In: Control Mechanisms for EcologicalEconomic Systems. Studies in Systems, Decision and Control, vol 10. Springer, Cham.

5. Korol, E.A., Kagan P.B., Khorkina, Zh.A. Ways to improve the efficiency of housing investment programs being implemented. Industrial and civil engineering. 2010. No. 10. P. 17-19.

6. Borkovskaya V.G. The concept of innovation for sustainable development in the construction business and education. Applied Mechanics and Materials. (Volumes 475476). Chapter 15: Engineering Management. December 2013. Pages 1703-1706. DOI: 10.4028/www.scientific.net/AMM.475-476.1703.

7. E.A. Korol, S.V. Komissarov, P.B. Kagan, S.G. Arutyunov. The Solution of problems of organizational-technological simulation of building processes. Industrial and civil engineering, 3 (2011).

8. Boris Titarenko, Amir Hasnaoui, Roman Titarenko. Risk management system model for construction projects. IOP Conference Series: Materials Science and Engineering, Volume 365, Safety in Construction.

9. BorkovskayaV.G, Passmore D. Behavioral engineering model to identify risks of losses in the construction industry. Advances in Economics, Business and Management Research (France-Netherlands). Atlantis Press. In press.

10. E.A. Korol, A.A. Pleshivtsev, The technology of construction of low-rise buildings from sandwich panels (2017).

11. Korol E.A., Kagan P.B. Komissarov S.V. Management of urban planning programs. Town planning. 2010. No. 4. P. 57-60.

12. Borkovskaya V.G., Degaev E., Burkova I. Environmental economic model of risk management and costs in the framework of the quality management system // MATEC Web of Conf., 193 (2018) 05027. DOI: https://doi.org/10.1051/matecconf/201819305027.

13. Annual report of a public corporation - the Housing and Utilities Reform Fund for 2017. On line: http://fondgkh.ru/workresult/cat/godovyie-otchetyi-fonda/

14. Leitch, M. "The Risk Management Gap", Board Leadership, vol. 2017, no. 154, pp. 13. doi:10.1002/bl.30088.

15. Borkovskaya V, Passmore D. Application of Failure Mode and Effects Analysis in Ecology in Russia. MATEC Web of Conf., 193 (2018) 05027. DOI: https://doi.org/10.1051/matecconf/201819305026

16. BorkovskayaV.G., Bardenwerper W., Roe R. Interactive Teaching of Risk Management in the Russian Construction Industry. IOP Conf. Series: Materials Science and Engineering 365 (2018) 062030 doi:10.1088/1757-899X/365/6/062030. 
17. Borkovskaya V.G, Bardenwerper W, Roe R. Sustainability Risk Management: The Case for Using Interactive Methodologies for Teaching, Training and Practice in Environmental Engineering and Other Fields. Advances in Economics, Business and Management Research (France-Netherlands). Atlantis Press. In press.

18. Degaev E.N. New classification of foaming agents for fire extinguishing // MATEC Web of Conferences 193, 02032 (2018). DOI: https://doi.org/10.1051/matecconf/201819302032.

19. Korol, E.A., Pugach, E.M., Kharkin, Yu.A. The influence of technological factors on the formation of communication layers of a multilayer enclosing structure. Vestnik MGSU.2014. 3

20. E. Korol, N. Shushunova, Green Roofs: Standardization and Quality Control of Processes in Green Construction. MATEC Web of Conferences 106, 06014 (2017) 